\title{
Individual Differences in Behavioral and Physiological Responsiveness of Primiparous Dairy Cows to Machine Milking
}

\author{
C. G. Van Reenen, ${ }^{*}$ J. T. N. Van der Werf, ${ }^{*}$ R. M. Bruckmaier,† H. Hopster, ${ }^{\star}$ B. Engel, ${ }^{\star}$ \\ J. P. T. M. Noordhuizen, $\ddagger$ and H. J. Blokhuis* \\ *Institute for Animal Science and Health (ID-Lelystad), P.O. Box 65, 8200 AB, Lelystad, The Netherlands \\ †Insitute of Physiology, Technical University of Munich, Weihenstephaner Berg 3, D-85350, Freising, Germany \\ ‡Department of Farm Animal Health, Faculty of Veterinary Medicine, Utrecht University, \\ P.O. Box 80151, 3508 TD Utrecht, The Netherlands
}

\section{ABSTRACT}

An experiment was performed in primiparous dairy cows $(n=23)$ to examine consistency of individual differences in reactivity to milking, and correlations between measures of behavior, physiology, and milk ejection. Responsiveness to milking was monitored during the first machine milking, on d 2 of lactation, and during milkings on d 4 and 130 of lactation. Measurements included kicking and stepping behavior, plasma cortisol and plasma oxytocin, heart rate, milk yield, milking time, milk flow rate, and residual milk obtained after administration of exogenous oxytocin. With repeated early lactation milkings, residual milk and the incidence of abnormal milk flow curves decreased. On d 130 of lactation all heifers exhibited normal milk ejection. Except for higher plasma cortisol concentrations on d 2 , all measures were consistent over time between $\mathrm{d}$ 2 and 4 of lactation as indicated by significant rank correlations. Individual differences in the behavioral response to udder preparation were consistent over time between early lactation milkings and d 130 of lactation. Residual milk, milk yield, maximum milk flow rate, plasma oxytocin and heart rate during udder preparation were similarly interrelated on d 2 and 4 of lactation. High heart rate responses on d 2 and 4 were associated with enhanced inhibition of milk ejection. In contrast, behavior recorded during the milking process was unrelated to ease of milk removal. Our results indicate that milking at the beginning of lactation may be stressful to some heifers, to the extent that milk ejection is inhibited, but less disturbing to others. The existence of consistent behavioral and physiological responses in the present study suggests that responsiveness of dairy heifers to milking is mediated by stable animal characteristics.

Received December 19, 2001.

Accepted April 26, 2002.

Corresponding author: C. G. Van Reenen; e-mail: c.g.vanreenen @id.wag-ur.nl.
(Key words: individual differences, milk ejection, behavior, stress, temperament)

\section{INTRODUCTION}

In dairy cows, disturbed milk ejection is common particularly during the first milkings of primiparous animals. One likely mechanism underlying this phenomenon involves stress-induced inhibition of oxytocin release (Bruckmaier and Blum, 1998; Tucker, 2000). The milking process constitutes several factors that may be stressful for naive periparturient heifers, including novelty and close interaction with a human handler. Milking cows in an unfamiliar environment has been shown to result in elevated levels of plasma cortisol, higher heart rates, reduced oxytocin release, and lower milk yields concomitant with an increase in the fraction of residual milk (Bruckmaier et al., 1993; Rushen et al, 2001). Reduced milk yields, higher residual milk fractions, and increased heart rates, together with an increase in stepping frequency with the hind legs during milking, have also been observed in cows milked in the presence of a human who had previously handled them aversively (Rushen et al., 1999).

In addition to environmental conditions, ease of milk removal and responsiveness to milking in heifers may also depend on qualities of the individual animal. Many studies report large (within-treatment) individual variation in behavioral and physiological reactions of dairy cows to milking (e.g., Schams et al., 1984; Bremner, 1997; Rushen et al., 1999; Tancin et al., 2001). There are two lines of evidence suggesting that such individual differences might reflect the existence of fundamental individual characteristics mediating cow reactivity. First, individual (dairy) cattle display consistent responses over time to treatments that contain aspects of environmental factors that may also be present during milking, such as handling (Kerr and Wood-Gush, 1987; Grandin, 1993) or exposure to novelty (Hopster, 1998). Consistent individual differences in responsiveness to environmental challenge in cattle have been proposed 
to indicate differences in temperament or fearfulness, which are believed to represent basic personality traits that may be accessible for genetic selection (Boissy, 1995; Grandin, 1997). Second, limited research implies possible relationships directly between personality or temperamental traits, and measures of milk ejection. Uvnäs-Moberg et al. (1990) obtained significant correlations between oxytocin levels primiparous women had in response to breast feeding and personality scores of anxiety. Likewise, Lyons (1989) found in dairy goats that stable individual differences in the behavioral expression of temperament (i.e., based on approach and avoidance of humans in test encounters, and behavior in the milking parlor) were associated with differences in residual milk fractions. Similar studies in dairy cows, addressing individual differences in (milking) temperament rather than differences between treatment groups, have been unable to demonstrate a relationship between parlor behavior and milk yield (Dickson et al., 1970; Purcell et al., 1988). However, these latter studies relied on subjective ratings made by herdsmen in commercial dairy herds, and did not include measures of physiology or milk ejection. Knowledge on behavioral and physiological determinants of (milking) temperament in dairy cows, and on the relationship between temperament and milk production characteristics such as yield and milking speed, is relevant to practical dairy industry, since it may enable the prediction of, for example, ease of milk removal based on other behavioral or physiological variables, and it may help to define a temperamental trait that could be used in genetic selection (see Schutz and Pajor, 2001).

The present experiment aimed to objectively assess, in a uniform group of dairy heifers, milk production characteristics and behavioral and physiological responses to milking, and to examine consistency of individual differences over milkings as well as correlations between measures of behavior, physiology, and inhibition of milk ejection. We hypothesized that especially at the beginning of lactation consistent individual differences may reflect dimensions of temperament, since heifers have been suggested to become accustomed to milking procedures somewhere between 7 to $40 \mathrm{~d}$ of lactation (Lefcourt and Barfield, 1995; Bremner, 1997). The identification of behavioral or physiological correlates of disturbed milk ejection was also expected to benefit understanding its underlying mechanism. Specifically, we measured heart rate, reflecting activity of the sympathetic nervous system, in conjunction with the release of plasma oxytocin in response to machinemilking, and were, therefore, able to address questions concerning the extent to which inhibition of milk ejection in dairy heifers is mediated by increased sympa- thetic activity, by central inhibition of oxyocin release, or both (Lefcourt, 1996; Bruckmaier and Blum, 1998).

\section{MATERIALS AND METHODS}

The present experiment was carried out at the experimental farm of ID-Lelystad, The Netherlands. The experiment had been approved of by the Institute's Animal Care and Use Committee.

\section{Animals, Housing, and Management}

Twenty-three primiparous Holstein-Friesian cows were used, all born and reared at the experimental farm of ID-Lelystad. During pregnancy the heifers were kept in the same group. One or two days before calving, heifers were transferred to individual calving pens. After calving, each heifer was housed in a separate straw-littered pen together with her calf, in a barn away from the calving area. The calf remained with the dam at least for the first $36 \mathrm{~h}$ after calving, and was allowed to suckle. Calves were removed at $0900 \mathrm{~h}$ on the second day after calving (i.e., on d 2 of lactation; day of calving is $\mathrm{d} 0$ ), and the heifers stayed in the individual pens until the afternoon when they were machine milked for the first time. Immediately after completion of the first machine milking, heifers entered a dairy herd of 60 cows that was housed in a cubicle barn. All heifers taking part in the present experiment calved over a 4mo period in the same calving season. Except for d 2 of lactation, the heifers were milked twice daily together with the rest of the herd, between $0515 \mathrm{~h}$ and $0615 \mathrm{~h}$ in the morning and between $1530 \mathrm{~h}$ and 1630 $\mathrm{h}$ in the afternoon.

All milkings took place in a fully automated doublethree open tandem milking parlor using De Laval milking equipment with electronic milk meters. The milking vacuum was set at $44 \mathrm{kPa}$. Pulsation rate was 60 cycles/ min with a 64:36 pulsation ratio. Clusters were automatically removed when milk flow dropped below 0.2 $\mathrm{kg} / \mathrm{min}$. Milking was performed by one of three milkers alternating milking on a 4-d basis. Cows were fed a total mixed diet for ad libitum intake consisting of maize silage, grass silage, concentrates, and minerals. In the milking parlor, cows received $1 \mathrm{~kg}$ of concentrates at a rate of $100 \mathrm{~g}$ per $21 \mathrm{~s}$.

\section{Experimental Milkings and Observations}

Responsiveness to milking was monitored in each heifer on three occasions:during the first machine milking, in the afternoon on d 2 of lactation, during the fifth milking, in the afternoon on $\mathrm{d} 4$ of lactation, and during one afternoon milking between $\mathrm{d} 110$ and 150 of lacta- 
tion (average: $\mathrm{d}$ 130). The distribution of calving dates over time allowed for a maximum of two heifers being tested on the same day.

On each day of testing at $1100 \mathrm{~h}$, heifers were subjected to a brief clinical inspection by a veterinarian, and an indwelling jugular catheter (1.4 m, polythene; Portex Ltd., Hythe, UK) was nonsurgically inserted via a 12-gauge needle (Intraflon, Vygon; Ecouen, France) and fitted into a custom-made pouch that was glued to the side of the neck of the animal and covered with an elastic neck bandage for further protection. Catheters were filled with citrate solution ( $0.1 \mathrm{M}$ in sterile physiological saline) to prevent blood clotting.

Thirty minutes prior to milking, a baseline blood sample was taken from the catheter, and heifers were fitted with a heart rate monitoring system (Polar Electro Oy, Helsinki, Finland), which recorded mean heart rates during 5-s intervals (Hopster and Blokhuis, 1994). Heart rate was continuously monitored until the end of milking. To allow undisturbed recording of pre-milking baseline heart rate on $d 4$ and 130 of lactation, heifers were kept in an area of the cubicle house adjacent to the waiting room in front of the milking parlor and separated from the rest of the herd by fences until the beginning of milking. At $1515 \mathrm{~h}$, the herd was collected in the waiting room and five cows were allowed to enter the milking parlor. Then the experimental heifer was taken individually to the milking parlor through the exit lane running alongside the waiting room, and placed in the remaining milking stall that was adapted for experimental purposes. Next, the milker started preparing the udder of the experimental heifer for 1 min according to a fixed protocol. Preparation consisted of $20 \mathrm{~s}$ of rhythmic and gentle stroking with the back of the right hand on the lower thigh of the left hind leg of the cow (approximately one up-and-down movement of the hand per second), followed by a period of 40 $\mathrm{s}$ of udder cleaning with a dry cotton towel. Appropriate timing was provided by an experimenter who was also present in the operating pit during milking, and engaged in collecting blood samples and recording times that marked relevant phases and events in the milking process with the use of a portable computer equipped with the Observer Software System for Behavioral Research (Noldus Information Technology, Wageningen, The Netherlands). Immediately after udder preparation a blood sample was taken, and the milking cluster was attached by the milker. Additional blood samples were taken every minute for the first $10 \mathrm{~min}$ after cluster attachment, and at 15 and $20 \mathrm{~min}$ after cluster attachment. Subsequently, 10 IU of oxytocin (Apharmo BV, Duiven, The Netherlands) was administered intravenously through the jugular catheter, and the milking cluster was reattached to obtain residual milk (Bruck- maier et al., 1993; Rushen et al., 2001). Finally, the heifer was released from the milking stall, retrieved by the experimenter at the end of the exit lane, and the heart rate monitor as well as the jugular catheter were removed. In case of a second heifer that needed to be tested, the previously described procedure was repeated from the moment an animal was taken to the milking parlor. Heart rate data were transferred to a personal computer afterward for further analyses.

Blood was collected into 10-mL evacuated tubes (Vacuette; Greiner BV, Alphen a/d Rijn, The Netherlands) containing heparin. Blood samples were held in ice water and centrifuged within $1 \mathrm{~h}$ after collection for 12 min at $2500 \times g$. Plasma was stored at $-20^{\circ} \mathrm{C}$ until assayed for cortisol (all samples) and oxytocin (all samples except those taken at 15 and $20 \mathrm{~min}$ after cluster attachment).

Behavioral responses of heifers to milking were observed by viewing video-taped recordings of milking sessions, obtained with the use of a camera that was mounted in the operating pit opposite to the experimental milking stall. Each instance of kicking or stepping with the hind legs was recorded. A kick was scored whenever a cow forcefully and rapidly moved one of the hind legs toward either the milker or the milking cluster. A step was defined as any other movement of one of the hoofs. Behavioral recordings were analyzed using the Observer software system for behavioral research (Noldus Information Technology).

Milk yield, maximum milk flow rate, and milking time were automatically recorded by the milking system and downloaded to a central computer. The milking glass of the milking stall used for milking experimental heifers was suspended from digital scales, and cumulative weight of the amount of milk was recorded every $5 \mathrm{~s}$ for the duration of milking. These data were processed at a later stage to obtain milk flow curves.

By manipulating the automatic control of the entrance doors of the milking parlor throughout episodes of testing, the milker made sure that experimental heifers remained in the milking stall for the appropriate length of time, and that the remaining milking stalls were occupied by other cows at all times. In order to minimize differences in treatment between heifers, milkers were instructed to behave as standardized as possible toward heifers during experimental milkings, i.e., to refrain from any physical contacts with the animals other than during udder preparation and replacing dislodged cups, and not to use a kick-bar to reduce kicking. During milkings other than the three experimental ones, heifers normally entered the milking parlor via the waiting room together with the rest of the herd, were free to choose any milking stall unless other 
heifers were tested, and received routine treatment by the milkers.

\section{Hormone Assays}

Plasma levels of cortisol were determined by a timeresolved fluoro immunoassay in unextracted bovine plasma (Erkens et al., 1998). Samples were run in duplicate. The intra-assay coefficients of variation for control samples with concentrations of $71.1,39.2$, and 10.3 ng. $\mathrm{ml}^{-1}$ were $8.2,7.9$, and $11.3 \%(\mathrm{n}=16)$, respectively. The corresponding inter-assay coefficients of variation were $10.7,11.4$, and $18.4 \%(\mathrm{n}=20)$. The lower detection limit for a $20-\mu \mathrm{L}$ sample was $0.5 \mathrm{ng} / \mathrm{mL}$. Concentrations of plasma oxytocin were analyzed using a radioimmunoassay developed by Schams (1983). Assay sensitivity was $0.3 \mathrm{pg} / \mathrm{mL}$. Intra-assay and inter-assay coefficients of variation were 8 and $11 \%$, respectively. Extraction recovery was over $70 \%$.

\section{Data Processing and Statistical Analyses}

Average heart rates were calculated during a 5-min baseline period between 5 and 10 min after starting the heart rate recording, during the 1-min period of preparation and during machine milking. We hypothesized that sustained increases of heart rate relative to baseline during udder preparation or milk ejection may affect milk ejection. Therefore, we calculated heart rate responses by subtracting baseline values from average heart rates during preparation and during milking, respectively. Kicks and steps were expressed as number per min during preparation and milking, respectively. Since preliminary analyses revealed that the number of kicks was significantly correlated with the number of steps both during preparation and during milking, we decided to consider the number of kicks and the number of steps plus kicks in each phase of the milking process as measures of behavioral responsiveness. For plasma cortisol and plasma oxytocin, integrated areas under the hormone against time after cluster attachment vs. hormone curves were calculated. Residual milk was expressed as a percentage of total milk, where the latter is the sum of the milk yield obtained during milking plus residual milk obtained after administration of exogenous oxytocin.

Milk flow curves ( $\mathrm{kg}$ milk/min against time) were derived from cumulative weights of the amount of milk recorded during milking, graphically depicted and qualitatively evaluated. Milk flow curves obtained in the present experiment were divided into three categories: those with a complete cessation of milk flow within 2 min after cluster attachment, those with a distinct and transient depression of milk flow within 2 min after attachment (i.e., bimodal curves), and curves not belonging to either of these latter two categories.

Behavioral measures, area under the curve for cortisol and oxytocin, oxytocin after preparation, heart rate responses, residual milk, milk yield, milking time and maximum milk flow rate obtained at each day of lactation were first analyzed with an analyses of variance model that included identity of the milker as a fixed effect. For non-normally distributed variables including fractions (i.e., residual milk) and count data (i.e., frequencies of behaviors), the binomial and Poisson variance functions were employed, respectively. The analyses were based on quasi maximum likelihood (McCullagh and Nelder, 1989). None of the variables were significantly affected by the identity of the milker, which was, therefore, not included as a source of variation in subsequent analyses. Differences between sampling times or days in lactation were calculated per animal and analyzed with Wilcoxon's matched pairs signed rank test. Tests on differences were performed to avoid the need for modeling complex dependence structures between data from the same animal. The rank test is based on minimal model assumptions, i.e., the common assumption of a shift alternative. For pairs of variables, observed either within or between days of lactation, Spearman rank correlations were calculated. Principal component analysis (PCA) was employed to analyze and objectively summarize relationships between multiple variables (Jolliffe, 1986). Variables were scaled prior to PCA, i.e., PCA was performed on the Pearson correlation matrix. Principal components produced by PCA are linear combinations of the original variables, and represent condensed new variables reflecting independent characteristics underlying the correlation matrix. The first component explains most of the variance (expressed in terms of the first eigenvalue), the second component explains most of the remaining variation, and so forth. The coefficients of the scaled variables, the so-called loadings, indicate the importance of each of the original variables for the principal components. A separate PCA was carried out on the data of each day of lactation. The residual milk fraction (p) was $\operatorname{logit}$-transformed $(\operatorname{logit}(\mathrm{p})=\log (\mathrm{p} / 1-\mathrm{p}))$ prior to inclusion in the PCA. Only principal components with eigenvalues larger than one were retained for further analyses.

All statistical calculations were performed with the statistical programming language Genstat (Genstat 5 Committee, 1993).

\section{RESULTS}

\section{Differences Between Days of Lactation}

On all days of testing, plasma cortisol continuously increased during the first $10 \mathrm{~min}$ after cluster attach- 
ment (Figure 1). Cortisol levels at $15 \mathrm{~min}$ were lower $(P<0.01)$ compared to levels at $10 \mathrm{~min}$ after cluster placement, and further declined $(P<0.01)$ over the next five min. As indicated by large standard errors, response patterns of plasma oxytocin were highly variable among individuals on all days of testing (Figure 1). On average, heifers sustained oxytocin levels elevated over baseline until at least $8 \mathrm{~min}$ after cluster attachment (Figure 1).

Means and standard errors of milk production characteristics and behavioral and physiological measures on respective days of lactation are presented in Table 1. Over days of lactation, the average residual milk fraction progressively decreased, and maximum milk flow rate and oxytocin after preparation increased. Measures of cortisol release decreased on $\mathrm{d} 4 \mathrm{in}$ comparison with $\mathrm{d} 2$. In contrast to oxytocin after preparation, the integrated amount of oxytocin generated after cluster attachment did not significantly alter in the course of lactation. Baseline heart rate was substantially lower on d 130 in comparison with d 2 and d 4. Except for heart rate change during milking, behavioral and cardiac responses were generally lowest on 4 relative to the other days of testing.

On d 2 of lactation, milk flow curves of the first (early cessation of milk flow) and second (bimodal) category were observed in two and eight heifers, respectively. On $d 4$, curves of the first category were no longer present, and two heifers exhibited curves of the second category. On d 130 of lactation, all milk flow curves were of the third category.

\section{Consistency of Measures over Time and Correlations Between Variables}

With the exception of milk yield, oxytocin after preparation, and cortisol concentrations, individual differences in all measures considered in the present report were consistent over time between $\mathrm{d} 2$ and 4 of lactation (Table 2). Individual differences in the behavioral response to udder preparation were consistent over time between early lactation milkings (d 2 and 4) and d 130 of lactation (Table 2).

Measures of cortisol release were not significantly correlated with behavioral measures or with measures of heart rate response. Only on $\mathrm{d} 2$ and 4, number of kicks during preparation was significantly correlated with heart rate change during preparation (rank correlations of 0.44 and 0.43 on $\mathrm{d} 2$ and 4 , respectively, $P$ $<0.05)$. Number of kicks during milking significantly correlated with heart rate change during milking on $d$ 4 (rank correlation $0.62, P<0.01$ ), but not on the other days of testing.
Plasma oxytocin $(\mathrm{pg} / \mathrm{ml})$
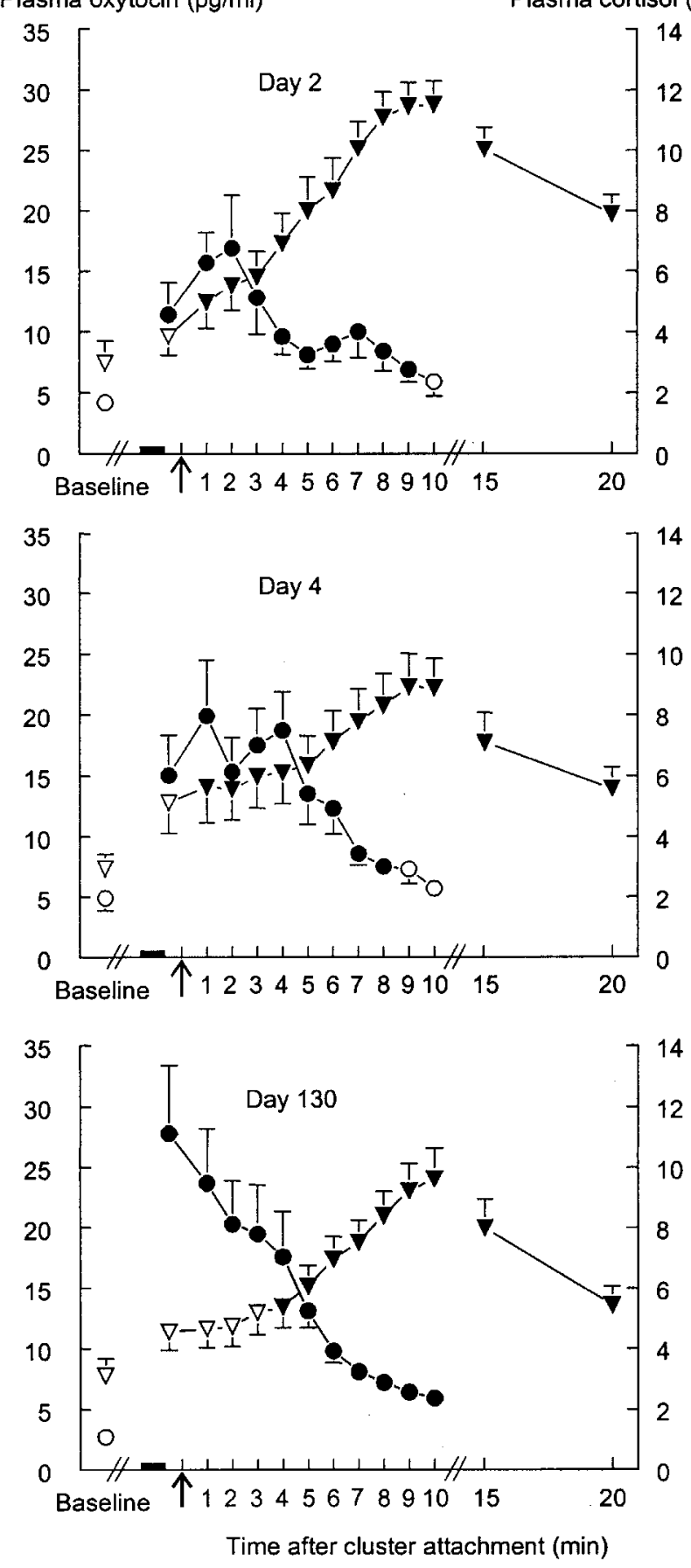

- : Preparation

Figure 1. Mean ( \pm SEM) plasma concentrations of oxytocin (circles) and cortisol (triangles) in primiparous dairy cows during milking sessions on d 2, 4, and 130 of lactation. Circles and triangles are closed when values differed significantly $(P<0.05)$ from baseline values. Arrow below $\mathrm{X}$-axis indicates the time of cluster attachment. 
Table 1. Milk production characteristics, and behavioral and physiological measures recorded in primiparous cows $(\mathrm{n}=23)$ during milking sessions on $\mathrm{d} 2,4$, and 130 of lactation.

\begin{tabular}{|c|c|c|c|c|c|c|}
\hline \multirow[b]{3}{*}{ Measure } & \multicolumn{6}{|c|}{ Day of lactation } \\
\hline & \multicolumn{2}{|c|}{ Day 2} & \multicolumn{2}{|c|}{ Day 4} & \multicolumn{2}{|c|}{ Day 130} \\
\hline & Mean & SEM & Mean & SEM & Mean & SEM \\
\hline Milk yield (kg) & $8.4^{\mathrm{a}, \mathrm{b}}$ & 0.88 & $7.2^{\mathrm{a}}$ & 0.39 & $10.6^{\mathrm{b}}$ & 0.36 \\
\hline Residual milk ( $\%$ of total milk ${ }^{1}$ ) & $34^{\mathrm{c}}$ & 5.2 & $18^{\mathrm{b}}$ & 3.7 & $9^{\mathrm{a}}$ & 0.9 \\
\hline Maximum milk flow rate $(\mathrm{kg} / \mathrm{min})$ & $3.2^{\mathrm{a}}$ & 0.26 & $4.2^{\mathrm{b}}$ & 0.24 & $4.7^{\mathrm{c}}$ & 0.28 \\
\hline Duration of milking (s) & $372^{\mathrm{b}}$ & 25.2 & $275^{\mathrm{a}}$ & 11.0 & $333^{\mathrm{b}}$ & 18.0 \\
\hline \multicolumn{7}{|l|}{ Kicks (number/min) } \\
\hline During preparation & $3.0^{\mathrm{b}}$ & 0.94 & $1.5^{\mathrm{a}}$ & 1.00 & $3.2^{\mathrm{b}}$ & 0.86 \\
\hline During milking & 0.7 & 0.17 & 0.7 & 0.20 & 0.4 & 0.08 \\
\hline \multicolumn{7}{|l|}{ Steps plus kicks (number/min) } \\
\hline During preparation & $4.4^{\mathrm{b}}$ & 1.37 & $1.8^{\mathrm{a}}$ & 1.10 & $5.7^{\mathrm{c}}$ & 1.46 \\
\hline During milking & $1.5^{\mathrm{a}, \mathrm{b}}$ & 0.25 & $1.3^{\mathrm{a}}$ & 0.31 & $2.3^{\mathrm{b}}$ & 0.40 \\
\hline Baseline heart rate (beats/min) & $97.6^{\mathrm{b}}$ & 1.73 & $98.1^{b}$ & 1.32 & $82.4^{\mathrm{a}}$ & 1.56 \\
\hline \multicolumn{7}{|l|}{ Heart rate change ${ }^{2}$ (beats/min) } \\
\hline During preparation & $12.0^{\mathrm{b}}$ & 1.60 & $4.6^{\mathrm{a}}$ & 1.01 & $9.7^{\mathrm{b}}$ & 1.25 \\
\hline During milking & $8.3^{\mathrm{b}}$ & 0.82 & $5.8^{\mathrm{a}, \mathrm{b}}$ & 1.39 & $4.2^{\mathrm{a}}$ & 1.13 \\
\hline Oxytocin after preparation $(\mathrm{pg} / \mathrm{mL})$ & $11.4^{\mathrm{a}}$ & 2.66 & $15.0^{\mathrm{a}, \mathrm{b}}$ & 3.33 & $27.8^{\mathrm{b}}$ & 5.57 \\
\hline Oxytocin 3 & 92.4 & 11.73 & 113.7 & 16.36 & 116.0 & 13.61 \\
\hline Cortisol $^{3}$ & $174.6^{\mathrm{b}}$ & 12.99 & $134.5^{\mathrm{a}}$ & 17.35 & $138.2^{\mathrm{a}, \mathrm{b}}$ & 13.08 \\
\hline Cortisol 10 min after attachment (ng/ml) & $11.5^{\mathrm{b}}$ & 0.78 & $8.9^{\mathrm{a}}$ & 0.96 & $9.6^{\mathrm{a}, \mathrm{b}}$ & 1.01 \\
\hline
\end{tabular}

${ }^{1}$ Total milk (kg): milk yield plus residual milk obtained after administration of exogenous oxytocin.

${ }^{2}$ Relative to baseline.

${ }^{3}$ Area under time after cluster attachment vs. hormone curve.

${ }^{\mathrm{a}, \mathrm{b}, \mathrm{c}}$ Means in the same row without a common superscript differ significantly $(P<0.05)$.

Individual differences in the behavioral response to preparation (i.e., kicks, and steps plus kicks) were not significantly associated with individual differences in the behavioral response to milking. In contrast, changes in heart rate during preparation were positively corre- lated with changes in heart rate during milking (rank correlations of $0.57,0.73$, and 0.73 on $\mathrm{d} 2,4$, and 130 , respectively, $P<0.01$ ).

Neither any behavioral measure nor any measure of plasma cortisol release was significantly correlated

Table 2. Spearman rank correlations over intervals between d 2, 4, and 130 of lactation, for milk production characteristics, and behavioral and physiological measures recorded during milking in primiparous cows $(\mathrm{n}=23)$.

\begin{tabular}{|c|c|c|c|}
\hline \multirow[b]{2}{*}{ Measure } & \multicolumn{3}{|c|}{ Interval between days of lactation } \\
\hline & Day $2-4$ & Day $2-130$ & Day $4-130$ \\
\hline Residual milk (\% of total milk) & $0.62^{* *}$ & 0.27 & 0.06 \\
\hline Maximum milk flow rate $(\mathrm{kg} / \mathrm{min})$ & $0.38 \dagger$ & $0.45^{*}$ & $0.41 \dagger$ \\
\hline Duration of milking (s) & $0.40 \dagger$ & 0.31 & $0.46^{*}$ \\
\hline \multicolumn{4}{|l|}{ Kicks (number/min) } \\
\hline During preparation & $0.82^{* *}$ & $0.45^{*}$ & $0.66 * *$ \\
\hline During milking & $0.42 *$ & 0.10 & 0.15 \\
\hline \multicolumn{4}{|l|}{ Steps plus kicks (number/min) } \\
\hline During preparation & $0.83 * *$ & $0.39 \dagger$ & $0.56 * *$ \\
\hline During milking & $0.46^{*}$ & 0.04 & 0.31 \\
\hline Baseline heart rate (beats/min) & $0.68 * *$ & -0.08 & -0.21 \\
\hline \multicolumn{4}{|l|}{ Heart rate change ${ }^{1}$ (beats/min) } \\
\hline During preparation & $0.59^{* *}$ & -0.33 & -0.21 \\
\hline During milking & $0.52 *$ & -0.08 & -0.17 \\
\hline Oxytocin ${ }^{2}$ & $0.70^{* *}$ & 0.28 & 0.21 \\
\hline Cortisol $10 \mathrm{~min}$ after attachment $(\mathrm{ng} / \mathrm{mL})$ & $0.40 \dagger$ & 0.22 & 0.27 \\
\hline
\end{tabular}

\footnotetext{
${ }^{1}$ Relative to baseline.

${ }^{2}$ Area under curve for oxytocin concentrations over time after cluster attachment.

$\dagger P<0.10$.

$* P<0.05$.

$* * P<0.01$
} 
Table 3. Spearman rank correlations ${ }^{1}$ between milk production characteristics, heart rate, and oxytocin recorded in primiparous cows $(\mathrm{n}=23)$ during milking sessions on $\mathrm{d} 2,4$, and 130 of lactation.

\begin{tabular}{|c|c|c|c|c|}
\hline Measure & 1 & 2 & 3 & 4 \\
\hline \multicolumn{5}{|l|}{ 1. Milk yield (kg) } \\
\hline \multirow{3}{*}{ 2. residual milk (\% of total milk) } & $-0.81^{*}$ & & & \\
\hline & $-0.37 \dagger$ & & & \\
\hline & $0.38 \dagger$ & & & \\
\hline \multirow{3}{*}{ 3. Maximum milk flow rate $(\mathrm{kg} / \mathrm{min})$} & $0.52 *$ & $-0.62 * *$ & & \\
\hline & $0.37 \dagger$ & $-0.36 \dagger$ & & \\
\hline & 0.08 & 0.15 & & \\
\hline \multirow[t]{3}{*}{ 4. Heart rate during preparation ${ }^{2}$} & $-0.47^{*}$ & $0.36 \dagger$ & $-0.36 \dagger$ & \\
\hline & -0.34 & $0.47^{*}$ & $-0.55^{* *}$ & \\
\hline & 0.12 & 0.00 & $0.46^{*}$ & \\
\hline \multirow[t]{3}{*}{ 5. Oxytocin ${ }^{3}$} & $0.68^{* *}$ & $-0.82^{* *}$ & $0.54^{* *}$ & $-0.49 *$ \\
\hline & $0.37 \dagger$ & $-0.72^{* *}$ & 0.34 & $-0.40 \dagger$ \\
\hline & 0.30 & -0.05 & $0.46^{*}$ & 0.29 \\
\hline
\end{tabular}

${ }^{1}$ Within each cell of the matrix, the correlations in the first, second, and third rows represent the correlations between measures obtained on $\mathrm{d} 2,4$, and 130 of lactation, respectively.

${ }^{2}$ Change relative to baseline (beats/min).

${ }^{3}$ Area under curve for oxytocin concentrations over time after cluster attachment.

$\dagger P<0.10$.

$* P<0.05$.

$* * P<0.01$

with the residual milk fraction. Residual milk, milk yield, maximum milk flow rate, oxytocin, and heart rate during preparation were interrelated on $\mathrm{d} 2$ and 4 of lactation (Table 3). The patterns of correlations between variables presented in Table 3 could be adequately summarized using principal component analyses (PCA). PCA successively performed on data recorded on d 2 and 4 of lactation, produced in each case a single component with eigenvalue larger than 1 . Eigenvalues were 3.11 and 2.74 , and percentages of total variance explained by the first principal component were 62 and $55 \%$ on $\mathrm{d} 2$ and 4, respectively. On d 130, PCA resulted in two components with eigenvalues larger than 1 (1.91 and 1.37), explaining 38 and $27 \%$ ( $65 \%$ in total) of the variation. Figure 2 shows the distribution of the variables included in the PCA in relation to the first two components. Both on $\mathrm{d} 2$ and 4 , heart rate during preparation and residual milk loaded positively, and milk flow, milk yield, and oxytocin loaded negatively on the first principal component (Figure 2). Therefore, this latter component was interpreted to reflect inhibition of milk ejection, with heifers having high component scores showing enhanced inhibition of milk ejection, and heifers having low component scores showing reduced inhibition of milk ejection. Importantly, individual differences in component scores of the first principal component obtained on d 2 of lactation significantly predicted individual differences in component scores of the first principal component obtained on d 4 (rank correlation 0.66, $P<0.01$ ), evidencing consistency over early lactation milkings of a multivariate response profile associated with milk ejection. There were no significant relationships between component scores of the first principal component on d 2 or 4 , and measures of behavior or cortisol release.

The pattern of interrelated responses that was present on d 2 and 4 of lactation was markedly changed on $\mathrm{d} 130$. In contrast to $\mathrm{d} 2$ and 4 , the residual milk fraction on d 130 was unrelated to oxytocin and tended to correlate positively with milk yield (Table 3 ), and exclusively loaded on the second principal component (Figure 2). In addition, also contrary to $\mathrm{d} 2$ and 4 , heart rate during preparation on d 130 was significantly positively correlated with maximum milk flow rate (Table 3), and, together with oxytocin, represented a group of closely interrelated variables constituting the first principal component (Figure 2). There were no significant correlations between any principal component score obtained on d 130 and scores of the first principal component derived after PCA on $\mathrm{d} 2$ and 4, respectively.

\section{DISCUSSION}

The main finding of the present study is that individual heifers showed consistent behavioral and physiological responses to standardized milkings at the beginning of lactation. This strongly suggests that responsiveness of dairy heifers to milking is mediated by stable animal characteristics. Not only individual differences in separate measures proved consistent over early lactation milkings, but also differences in an aggregate measure composed of a weighted combination of interrelated variables, putatively reflecting inhibition of milk ejection. This would indicate that multiple 


\section{Component 2}
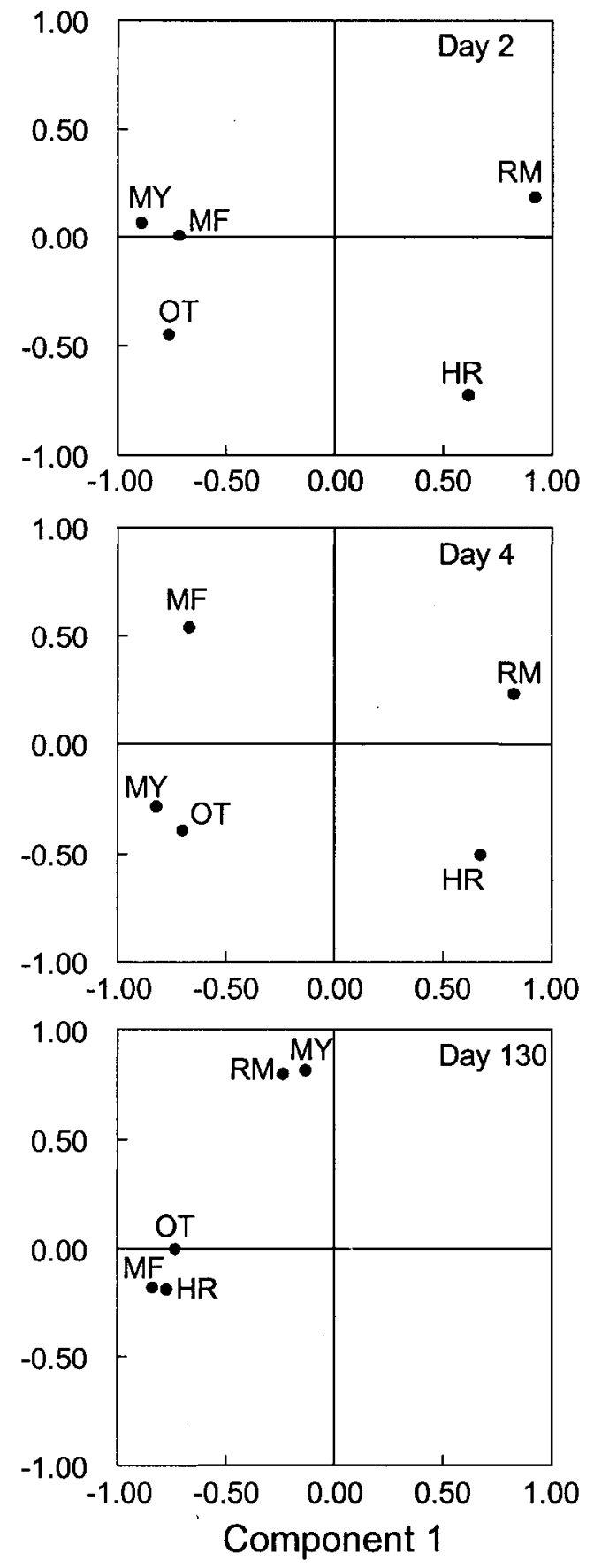

Figure 2. Distributions in relation to the first two principal components extracted after principal component analyses of variables obtained during milkings of heifers on d 2, 4, and 130 of lactation, with loadings of each variable on the first and second principal component serving as coordinates on the $\mathrm{X}$-axis and $\mathrm{Y}$-axis, respectively. Labels of variables: $\mathrm{MY}=$ milk yield; $\mathrm{MF}=$ maximum milk flow rate; $\mathrm{OT}=$ integrated area under the curve for plasma oxytocin by time after cluster attachment; $\mathrm{HR}=$ heart rate change during udder preparation relative to baseline; $\mathrm{RM}=$ residual milk fraction. variables were consistently mediated by the same underlying characteristic or mechanism across milkings.

The pattern of correlations on d 2 and 4 of lactation reported here fits the mechanism of stress-induced inhibition of milk ejection that has been found in cows milked in an unfamiliar environment (Bruckmaier et al., 1993, Rushen et al., 2001). Residual milk fraction was highly negatively correlated with oxytocin released after cluster attachment, providing evidence for inhibition of oxytocin secretion in those heifers with reduced milk letdown. The coherent interrelationships between measures of milk ejection and heart rate change during preparation, with high heart rate responses associated with enhanced inhibition of milk ejection, suggest the involvement of activation of the sympathetic nervous system in the mechanism underlying perturbed milk removal in our heifers. Increased sympathetic activity, and the release of catecholamines, may result in peripheral inhibition of milk ejection through interference with oxytocin efficacy at the level of the mammary gland (Lefcourt, 1996). This mechanism is usually distinguished from central inhibition of milk ejection by suppression of oxytocin release (Bruckmaier and Blum, 1998; Tucker, 2000). The present data, however, suggest a possible link between increased sympathetic activity and central inhibition of milk ejection. In agreement with our findings, Lefcourt et al. (1997) demonstrated an inverse relationship between noradrenalin concentrations prior to milking and oxytocin responses in dairy ewes, and proposed that peripheral concentrations of noradrenalin should be considered a marker of sympathetic input to hypothalamic mechanisms in control of oxytocin release. Measuring heart rate simultaneously with plasma catecholamines would be a necessary step to examine whether a similar mechanism operates in periparturient heifers during milking.

The sympathetic nervous system may also represent a possible connection between inhibition of milk ejection and basic features of personality such as temperament or fearfulness. In cattle, both novelty and exposure to people can elicit an emotional state of fear that is characterized physiologically by increased activity of the sympathetic nervous system, and is assumed to be modulated by underlying personality traits defining the vulnerability of an individual to respond (Boissy, 1995; Grandin, 1997). Thus, it is suggested that sympathetic activity prior to and during milking may have been highest in the most fearful heifers, causing the greatest disturbances in oxytocin release and milk removal. Given the relevance in the present study of heart rate change during preparation, when there is close contact between human and cow, fear of people might be important in this respect. In support of a relationship 
between fearfulness and inhibition of milk removal are studies in dairy goats (Lyons, 1989) and breast-feeding women (Uvnäs-Moberg et al., 1990), showing high residual milk fractions in goats fearful of people, and lowsuckling-induced oxytocin levels in women with high anxiety scores.

Behaviors during preparation were not correlated with behaviors during milking. This means that individual heifers responded differently to different phases in the milking process, and may reflect the difference between preparation and milking in the degree of human contact. The incidence of leg movements in dairy cows, including steps and kicks, occurring in the close presence of the milker has been hypothesized to be positively associated with the level of fear of humans and, on the assumption of a negative fear-productivity relationship, to be negatively associated with milk yield (Hemsworth et al., 1989, Breuer et al., 2000). However, in our experiment there were no relationships in heifers between behavioral measures recorded in the milking parlor and residual milk or an aggregate measure of milk ejection, despite significant (although mostly moderate) correlations between the incidence of kicking and heart rate change during preparation or milking. This finding seems to confirm previous studies in dairy cattle, showing no relationship between parlor behavior and milk yield (Dickson et al., 1970; Purcell et al., 1988). Moreover, Purcell et al. (1988) failed to establish a relationship between the distance individual cows kept to a stationary human, a behavioral measure which is assumed to reflect the level of fear of humans (Hemsworth et al., 1989; Rushen et al., 1999; Breuer et al., 2000), and their behavior in the milking parlor. Taken together, results in dairy cows appear to contrast with results in dairy goats that revealed significant interrelations between avoidance behavior in the presence of a human, behavior in the milking parlor and residual milk (Lyons, 1989).

To explain the lack of association in dairy cows between behavior and measures of milk ejection or milk yield, Rushen et al. (2001) suggested that different behavioral and physiological responses may be affected independently by different aspects of the milking process. This suggestion would be plausible if, for example, our results would have pointed to inhibition of milk ejection primarily due to the novelty associated with machine milking, and variation in behavioral responses occurring mainly during periods of interaction with a human. However, both the heart rate response that appeared to be implicated in the inhibition of milk removal and the behavioral response that was not related to measures of milk ejection were recorded during the same phase of the milking process, i.e., udder preparation. Bremner (1997) proposed that there is a nonlinear relationship in heifers between tameness and behavioral reactivity, with both very tame and very fearful animals being less likely to step or kick during milking, which could provide an alternative explanation for the absence of significant (linear) correlations between measures of behavior and milk ejection. However, on the assumption that heifers with the most disturbed milk removal at the beginning of lactation were the most fearful ones and vice versa, this explanation does not seem to apply to our findings since nonlinear patterns of association between behavioral responses and measures of milk ejection could not be found (results not shown). Thus, both heifers with enhanced and reduced inhibition of milk ejection were equally likely to consistently exhibit either high or low levels of leg movements. Therefore, we postulate that during early lactation milkings different heifers expressed the same underlying tendency, probably fearfulness, similarly from a physiological point of view, i.e., by an inhibition of oxytocin release proportionate to the level of fear, but differentially in terms of behavior, i.e., by performing a variable but individually stable number of leg movements. In line with this suggestion, Boissy (1995) argued that an emotional state of fear may be accompanied by various, sometimes even contradictory, patterns of behavior in the range between active avoidance (i.e., flight, escape) and immobility. Variability in behavioral patterns during milking among putatively nonfearful heifers, i.e., animals with reduced inhibition of milk removal, may originate from individual differences in (the expression of) temperamental characteristics other than fearfulness which have also been suggested to mediate cow behavior during milking, such as aggressiveness or boldness (Purcell et al., 1988; Rushen et al., 1999). The possibility of differential behavioral but similar physiological responses to fear-evoking stimuli during milking in dairy cows is supported by data from Knierim and Waran (1993) showing increased heart rates and reduced milk yields, but no significant behavioral changes, when the same cows were milked by relief milkers instead of the usual milkers.

The present experiment provided little evidence for consistency over milkings in measures of cortisol release, or for the existence of relationships between measures of cortisol release and other variables. These findings confirm previous studies in support of inhibition of oxytocin release independent of cortisol (Mayer and Lefcourt, 1987; Marnet and Negrao, 2000), but also suggest that plasma cortisol may not be very useful to characterize individual differences in stress responsiveness in the context of milking. The feasability of plasma cortisol as a sensitive indicator of stress-induced activation of the hypothalamo-pituitary adrenal 
axis during milking is probably hampered by the fact that (machine) milking of dairy cows as such stimulates the release of cortisol, which is required for maintenance of lactation (Tucker, 2000). In fact, patterns of milking-induced cortisol release in the present study were similar to the patterns observed by Gorewit et al. (1992) in normal multiparous cows, with peak levels of cortisol 10 min after cluster attachment. Long-lasting elevations of plasma cortisol with maximum levels some 45 min after the beginning of milking were found by Rushen et al. (2001) in dairy cows milked individually in a novel environment, and may be a reflection predominantly of the effect of social isolation since our heifers were milked in the presence of other cows.

Disturbances in milk removal seemed to disappear fairly quickly across early lactation milkings in our study, as illustrated by large decreases in the number of abnormal milk flow curves and in the average residual milk fraction on $\mathrm{d} 4$ relative to $\mathrm{d} 2$ of lactation. This agrees with the study of Bremner (1997) where the incidence of heifers with disturbed milk letdown was found to decline by at least $50 \%$ over the first week of lactation. Likewise, during the sixth milking in a series of successive milkings of cows in an unfamiliar environment, milk flow and milk yield were normalized, and plasma cortisol was decreased in comparison with the first milking, suggesting a rapidly progressing process of adaptation to environmental challenge (Bruckmaier et al., 1996). Correspondingly, we found lower levels of plasma cortisol with repeated early lactation milkings, together with lower heart-rate responses and lower average numbers of leg movements. This latter finding would suggest that adaptation to milking may involve a reduction of all leg movements regardless of the underlying emotional state (e.g., fearfulness, aggressiveness, boldness).

On d 130 of lactation, the average residual milk fraction was $9 \%$, which is a level that is characteristic of normal and undisturbed milk ejection (Bruckmaier and Blum, 1998). The pattern of correlations between various measures was fundamentally changed on d 130 relative to $\mathrm{d} 2$ and 4 , since residual milk and heart rate during preparation no longer counteracted milk yield, milk flow rate, and oxytocin. Instead, heart rate was positively correlated with measures of milk ejection, and residual milk was unrelated to oxytocin. This latter result has been interpreted as a finding confirming the theory that beyond a certain threshold level, any additional oxytocin has no further effect on milk removal (Schams et al., 1984; Bruckmaier and Blum, 1998). Notably, individual differences in the behavioral response to preparation, but not to milking, were consistent over time between early lactation milkings and d 130 of lactation, which agrees with long-term consistency in the behavioral reaction of heifers to being touched by a person as reported by Kerr and Wood-Gush (1987). Thus, individually stable behavioral patterns were clearly maintained beyond early lactational stages, but they were no longer accompanied by physiological disturbances due to stress on d 130 of lactation. In the case of previously fearful heifers, a process of learning may have taken place, whereby a persistent behavioral response to a fearful situation is gradually associated with reduced aversiveness, and eventually becomes detached from physiological signs of fear. This mechanism has been proposed to explain the observations that defecation and urination in dairy cows during mildly aversive treatments by handlers decreased as the treatment was repeated, and that residual milk was not affected by the presence during milking of the aversive handler, even though distance scores (i.e., behaviorally expressed levels of avoidance of a human) remained high (Munksgaard et al., 2001).

\section{CONCLUSIONS}

Individual primiparous dairy cows responded consistently to milking at the beginning of lactation, both behaviorally and physiologically. Our results indicate that milking at the beginning of lactation may be stressful to some heifers, to the extent that milk ejection is inhibited, and less disturbing to others. Consistent individual differences in responsiveness of heifers to milking may point to the existence of basic temperamental traits mediating reactivity to challenge in individual cows. In contrast to heart rate, behavior recorded during the milking process was unrelated to ease of milk removal in heifers, emphasizing the need for a multivariate approach in defining a desired (milking) temperament.

\section{ACKNOWLEDGMENTS}

We thank Henk Sulkers, Hans ter Heerd, and Jan Truin for skillful milking, Ben Berghuis for adjustment of the milking equipment and optimizing automatic data sampling, Albert Postma for analyzing milk flow data, Willem Buist for statistical support, and Hotze Wiersma for excellent veterinary assistance.

\section{REFERENCES}

Boissy, A. 1995. Fear and fearfulness in animals. Q. Rev. Biol. 70:165-191.

Bremner, K. J. 1997. Behaviour of dairy heifers during adaptation to milking. Proceedings of the New Zealand Society of Animal Production 57:105-108.

Breuer, K., P. H. Hemsworth, J. L. Barnett, L. R. Matthews, and G. J. Coleman. 2000. Behavioural response to humans and the productivity of commercial dairy cows. Appl. Anim. Beh. Sci. $66: 273-288$. 
Bruckmaier, R. M. and J. W. Blum. 1998. Oxytocin release and milk removal in ruminants. J. Dairy Sci. 81:939-949.

Bruckmaier, R. M., H. U. Pfeilsticker, and J. W. Blum. 1996. Milk yield, oxytocin and $\beta$-endorphin gradually normalize during repeated milking in unfamiliar surroundings. J. Dairy Res. 63:191-200

Bruckmaier, R. M., D. Schams, and J. W. Blum. 1993. Milk removal in familiar and unfamiliar surroundings:concentrations of oxytocin, prolactin, cortisol, and $\beta$-endorphin. J. Dairy Res. 60:449-456.

Dickson, D. P., G. R. Barr, L. P. Johnson, and D. A. Wieckert. 1970 Social dominance and temperament of holstein cows. J. Dairy Sci. 53:904-907.

Erkens, J. H. F., S. J. Dieleman, R. A. Dressendörfer, and C. J. Strassburger. 1998. A time-resolved fluoroimmunoassay for cortisol in unextracted bovine plasma with optimized procedures to eliminate steroid binding protein interference and to minimize nonspecific streptavidin-europium binding. J. Steroi. Biochem. Molec. Biol. 67:83-97.

Genstat 5 Committee. 1993. Reference Manual (Release 3). Clarendon Press, Oxford, UK.

Gorewit, R. C., K. Svennersten, W. R. Butler, and K. Uvnäs-Moberg. 1992. Endocrine responses in cows milked by hand and machine. J. Dairy Sci. 75:443-448.

Grandin, T. 1993. Behavioural agitation during handling of cattle is persistent over time. Appl. Anim. Beh. Sci. 36:1-9.

Grandin, T. 1997. Assessment of stress during handling and transport. J. Anim. Sci. 75:249-257.

Hemsworth, P. H., J. L. Barnett, A. J. Tilbrook, and C. Hansen. 1989. The effects of handling by humans at calving and during milking on the behaviour and milk cortisol concentrations of primiparous dairy cows. Appl. Anim. Beh. Sci. 22:313-326.

Hopster, H. 1998. Coping strategies in dairy cows. Ph.D. Diss., Agricultural Univ. Wageningen, The Netherlands.

Hopster, H., and H. J. Blokhuis. 1994. Validation of a heart rate monitor for measuring a stress response in dairy cows. Can. J. Anim. Sci. 74:465-474.

Jolliffe, I. T. 1986. Principal component analyses. Springer-Verlag, New York.

Kerr, S. G. C., and D. G. M. Wood-Gush. 1987. The development of behaviour patterns and temperament in dairy heifers. Behav. Processes. 15:1-16.

Knierim, U., and N. K. Waran, 1993. The influence of the humananimal interaction in the milking parlour on the behaviour, heartrate, and milk yield of dairy cows. Pages 169-173 in Proc. 27th International Congress on Applied Ethology, Berlin, Germany.

Lefcourt, A. M. 1996. Effects of stress on dairy cows with special reference to milk removal and stray voltage. Pages 43-48 in Proceedings of the Symposium on Milk Synthesis, Secretion and Removal in Ruminants. J. W. Blum and R. M. Bruckmaier, ed. University of Berne, Berne, Switzerland.
Lefcourt, A. M., and R. Barfield. 1995. Acclimation to milking of heifers raised as calves under conditions of intensive or restricted handling. J. Dairy Sci. 78 (Suppl. 1):178 (Abstr.).

Lefcourt, A. M., G. Paul, H. Mayer, D. Schams, and R. M. Bruckmaier. 1997. Response of catecholamines to manual teat stimulation or machine-milking of Lacune and Friesen dairy ewes. J. Dairy Sci. 80:3205-3211.

Lyons, D. M. 1989. Individual differences in temperament of dairy goats and the inhibition of milk ejection. Appl. Anim. Beh. Sci. 22:269-282

Marnet, P. G., and J. A. Negrao. 2000. The effects of a mixed-management system on the release of oxytocin, prolactin, and cortisol in ewes during suckling and machine milking. Reprod. Nutr. Dev. 40:271-281.

Mayer, H. K., and A. M. Lefcourt. 1987. Failure of cortisol injected prior to milking to inhibit milk ejection in dairy cattle. J. Dairy Res. 54:173-177.

McCullagh, P., and J. A. Nelder. 1989. Generalized linear models. Second Edition. Chapman and Fall, London.

Munksgaard, L., A. M. De Passillé, J. Rushen, M. S. Herskin, and A. M. Kristensen. 2001. Dairy cows' fear of people:social learning, milk yield and behaviour at milking. Appl. Anim. Beh. Sci. 73:15-26.

Purcell, D., C. W. Arave, and J. L. Walters. 1988. Relationship of three measures of behavior to milk production. Appl. Anim. Beh. Sci. 21:307-313.

Rushen, J., A. M. De Passillé, and L. Munksgaard. 1999. Fear of people by cows and effects on milk yield, behavior, and heart rate at milking. J. Dairy Sci. 82:720-727.

Rushen, J., L. Munksgaard, P. G. Marnet, and A. M. De Passillé. 2001. Human contact and the effects of acute stress on cows at milking. Appl. Anim. Beh. Sci. 73:1-14.

Schams, D. 1983. Oxytocin determination by radioimmunoassay. III. Improvement to subpicogram sensitivity and application to blood levels in cyclic cattle. Acta Endocrinologica 103:180-183.

Schams, D., H. Mayer, A. Prokopp, and H. Worstorff. 1984. Oxytocin secretion during milking in dairy cows with regard to the variation and importance of a threshold level for milk removal. J. Endocrinol. 102:337-343.

Schutz, M. M., and E. A. Pajor. 2001. Genetic control of dairy cattle behavior. J. Dairy Sci. 84 (E. Suppl.):E31-E38.

Tancin, V., W. D. Kraetzl, D. Schams, and R. M. Bruckmaier. 2001. The effect of conditioning to suckling, milking and of calf presence on the release of oxytocin in dairy cows. Appl. Anim. Beh. Sci. 72:235-246.

Tucker, H. A. 2000. Neuroendocrine regulation of lactation and milking. Pages 163-180 in Neuroendocrinology in Physiology and Medicine. P. M. Conn and M. E. Freeman, ed. Humana Press, Totowa, New Jersey.

Uvnäs-Moberg, K., A. M. Widström, E. Nissen, and H. Björvell. 1990. Personality traits in women 4 days post partum and their correlation with plasma levels of oxytocin and prolactin. J. Psychosom. Obst. Gynaecol. 11:261-273. 